\title{
The Phenomenon of Lysogenicity in Staphylococci
}

\author{
By PHYLLIS M. ROUNTREE* \\ Staphylococcal Reference Laboratory, Central Public Health Laboratory, \\ Colindale, London
}

SUMMARY: Of thirty coagulase-positive staphylococci, twenty-seven proved to be lysogenic. Free phage was found in filtrates of 4-5 hr. broth cultures of the lysogenic strains. The phages from six of these strains were examined by estimation of the amounts occurring in filtrates, for serology and for their range of lytic reactions with indicator strains. A number of strains were found which carried as many as five distinct bacteriophages. Probable phage mutations were also demonstrated. Interference effects due to lysogenicity were not a marked feature of the strains investigated.

It is assumed that the free phage released by the lysogenic strains is responsible for infection of sensitive indicator strains. The approximate proportion of lysogenic cells capable of releasing phage has been determined for three strains; it varied for the three strains and according to the indicator strains used, ranging from $1 / 3$ cells inoculated to $1 / 30,000$ cells inoculated. The mechanism of the release is probably due to multiplication of the phage in a number of lysogenic cells with consequent lysis of the cells and release of the phage.

Lysogenicity appeared to be a permanent feature of these strains. Every cell was apparently carrying phage and treatment with heat, with specific antibacteriophage serum, or by growth in broth containing sodium citrate did not make the cells non-lysogenic. For such strains, apart from an extracellular release of phage from a few cells in each culture, there is postulated an intracellular transference of phage to each daughter cell at cell division.

It has already been shown by Fisk (1942), Wilson \& Atkinson (1945) and Williams Smith $(1948 a, b)$, that a large number of strains of coagulase-positive staphylococci are lysogenic; that is to say, when cultures of these strains are grown on agar plates together with strains sensitive to the bacteriophages present in the lysogenic cultures, evidence of lytic action appears and the bacteriophages responsible may be isolated.

Williams Smith examined twenty-two strains used by Wilson \& Atkinson as propagating strains for their typing phages, and found seventeen of them to be lysogenic. By means of cross-resistance tests carried out according to Bail's technique, he showed that the range of phages lysing a given strain could be restricted by the development of resistant variants of the strain. These variants were often lysogenic; this was clearly shown in the case of non-lysogenic cultures which developed lysogenic, resistant variants. He concluded that the carriage of a phage by a given strain precluded its lysis by that phage. He was able to alter the pattern of phage reactions of certain strains by growing two different lysogenic cultures together in broth for prolonged periods; the altered strains presumably acquired the phage of the strain with which they had been growing. He was of the opinion that acquired phage resistance was responsible for the classification of many originally identical strains as different phage types.

* Permanent address: Fairfax Institute of Pathology, Royal Prince Alfred Hospital, Sydney, Australia. 
Since the observation (Rountree, 1947a) of two mutually lysogenic cultures which were apparently carrying identical bacteriophages did not agree with the interference effects reported by Williams Smith, further investigations have been made on the phenomena of lysogenicity in the staphylococci. There are also contradictory reports in the literature on the presence of free phage in filtrates of broth cultures of staphylococci. Callow (1922) stated that she could obtain bacteriophage by the filtration of staphylococcal cultures. Burnet \& Lush (1936) described a lysogenic mutant of a white staphylococcus which liberated bacteriophage in young and old cultures. On the other hand, Fisk (1942) and Williams Smith (1948b) failed to demonstrate the presence of bacteriophage in filtrates of lysogenic cultures.

The phenomena of lysogenicity as exhibited by the staphylococci may throw some light on the problems associated with the modes of reproduction of latent viruses generally, whether in bacterial or animal cells. An attempt has therefore been made to demonstrate the mechanisms determining the maintenance of the lysogenic state in the staphylococcal cell and the infection of indicator strains when placed in contact with lysogenic cultures.

\section{MATERIALS}

Thirty-four strains of coagulase-positive staphylococci, producing various amounts of pigment and of $\alpha$ and/or $\beta$ toxin, were used.

(a) Twenty-one strains used in this laboratory for the propagation of the typing bacteriophages.

(b) Two strains used in the serological differentiation of staphylococci, Christie \& Keogh's type 5 culture (1940) and 789, a culture identical with Cowan's type II (1939).

(c) Five lysogenic strains, S 14, S17, S 21, S33 and S 35 (Rountree, 1947a).

(d) Two lysogenic strains, S 58, and S59, isolated from human infections.

(e) Four strains, S11, S50, B83 and R 192, whose lysogenicity was not investigated but which served as indicator strains sensitive to certain of the bacteriophages encountered.

\section{RESULTS}

\section{Presence of bacteriophage in filtrates of lysogenic cultures}

A number of previous experiments had confirmed the fact that bacteriophage could not be demonstrated in filtrates of $18 \mathrm{hr}$. broth cultures of known lysogenic strains. However, it was found that phage could be demonstrated in broth cultures of such strains by the following method. A fairly heavy inoculum of cells was grown in Todd-Hewitt (1932) broth at 37 for 4-5 hr., after which period obvious turbidity had developed. The cultures were centrifuged for $10 \mathrm{~min}$. at $\mathbf{3 0 0 0}$ r.p.m. and filtered through gradocol membranes of an A.P.D. of $0.84 \mu$. The filtrates were then tested for bacteriophage against a series of strains known to be sensitive on agar plates to the lysogenic strain. Free phage was detected in filtrates from twenty-five of the thirty strains tested (Table 1). In the three strains 18, 284 and 1351, in which no free phage 
could be detected, it is possible that the available indicator strains were not suitable. In two other strains, S14 and S21, known to be lysogenic on agar, no free phage could be detected. Filtrates of S14 were also tested to see if they contained any inactivating agent for the phage (14/17) carried by this strain, but no evidence of inactivation could be found when such filtrates were mixed with phage $14 / 17$ and incubated at $37^{\circ}$ for $2 \mathrm{hr}$.

Table 1. Indicator strains of Staph. aureus sensitive to bacteriophages carried by twenty-seven lysogenic strains of Staph. aureus

\begin{tabular}{|c|c|}
\hline $\begin{array}{l}\text { Lysogenic } \\
\text { strain }\end{array}$ & Indicator strains \\
\hline 3 & 36, S59 \\
\hline 4 & S50, S59 \\
\hline 33 & S59, B 83 \\
\hline 36 & $3,1307, \mathbf{S} 59$ \\
\hline 144 & 18,373, S 59, B 83 \\
\hline 145 & $211,284,1339$, S 17, CK5 \\
\hline 211 & 284, 1339, CK5 \\
\hline 373 & 2329 \\
\hline 761 & 3,18 \\
\hline 925 & 2329 \\
\hline 987 & $3,36,1351$, S59 \\
\hline 1163 & $3,36, \mathbf{S} 59$ \\
\hline 1307 & $\mathbf{3}, \mathbf{R} 1760$ \\
\hline 1339 & 145, 211, S17, CK5, 789 \\
\hline
\end{tabular}

\begin{tabular}{|c|c|}
\hline $\begin{array}{l}\text { Lysogenic } \\
\text { strain }\end{array}$ & Indicator strains \\
\hline 1363 & 18, R 192 \\
\hline 1670 & 36, R1760, R 192 \\
\hline R1760 & $3,36, \mathrm{~S} 59$ \\
\hline 2329 & $\mathbf{3}, \mathbf{S} 59$ \\
\hline S 14 & S17 \\
\hline S17 & $211,284,1339$ \\
\hline S21 & S11 \\
\hline S33 & 3, $\mathbf{S 3 5}$ \\
\hline S35 & 3, S33 \\
\hline S58 & S50, S59, B83 \\
\hline S59 & 3, R1760, 2329 \\
\hline CK5 & $145,211,284,1339, \mathrm{~S} 17$ \\
\hline 789 & $145,211,284,1339$ \\
\hline
\end{tabular}

Exact estimations of the amount of phage $/ \mathrm{ml}$. of each filtrate were not made in all cases, but in those in which it was carried out there was a wide variation from strain to strain, the counts varying from 50 to 7,000,000 phage particles $/ \mathrm{ml}$.

There were many cases of mutual lysogenicity among the thirty strains; for example, 3 and S 59, 3 and 36, R 1760 and S 59, S 33 and S 35, 145 and 1339, and 211 and 1339. In all cases, the filtrates from lysogenic strains produced no plaques when tested on agar plates inoculated with the strains used for the preparation of the filtrates.

Burnet \& Lush (1935) showed that the staphylococcal bacteriophages which they classified as strong or intermediate were absorbed by all 'aureus' staphylococci tested, whether they lysed these strains or not. This was confirmed for the phages used in the typing of staphylococci (Rountree, 1947b). The failure to demonstrate free bacteriophage in older cultures of lysogenic strains may, therefore, be ascribed to its absorption on to the bacterial cells. In the two lysogenic strains from which no detectable phage was released in broth cultures, it is possible that the phage was more quickly reabsorbed than was the case with the other strains, since it was later shown that S14 probably did release free phage.

\section{Bacteriophage carried by six closely related strains}

From the thirty strains, seven were selected which were closely related, both in their reactions with the typing phages and in their lysogenic interreactions. These were 145, 211, 284, 1339, S17, CK5 and 789. Strain 284 was not detectably lysogenic; the other six strains were (Table 2 ). 
The bacteriophages carried by each of these six strains were prepared against the susceptible strains listed in column 3 of Table 2, making a total of twenty-five phages. They were isolated from plates made by Fisk's method, re-isolated at least twice from single plaques and the filtrates prepared in the usual way. The dilution of bacteriophage filtrate just giving confluent lysis on agar with its homologous staphylococcus was tested against all seven strains. The serological type of the bacteriophages was also determined, since it has been shown (Rountree, 1949) that two serological groups (A and B) can be

Table 2. The reactions with typing phages and the lysogenic interreactions of seven closely related strains of Staph. aureus

\begin{tabular}{|c|c|c|}
\hline no. & Reactions with typing phages & $\begin{array}{l}\text { Strains susceptible to phage } \\
\text { carried by the strain }\end{array}$ \\
\hline 145 & $\mathbf{3 B}+, 5 \mathbf{1}++++$ & $211,284,1339, \mathrm{~S} 17, \mathrm{CK} 5$ \\
\hline 211 & $\mathbf{3 B}++++, 3 \mathrm{C}++$ & 284,1339 , CK5 \\
\hline 284 & $\mathbf{3} \mathbf{A}++++, \mathbf{3} \mathbf{B}+, \mathbf{3} \mathbf{C}+$ & 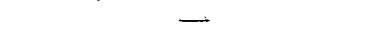 \\
\hline 1339 & $3 \mathrm{~B}+, \mathbf{3 C}++++$ & 145,211, S17, CK5, 789 \\
\hline S17 & $3 \mathrm{~B}+, 3 \mathrm{C}+, 14+t+t$ & $211,284,1339$ \\
\hline CK5 & $3 \mathrm{~B}++, 3 \mathrm{C}++$ & $145,211,284,1339, \mathrm{~S} 17$ \\
\hline 789 & $\mathbf{3 B}++++$ & $145,211,284,1339$ \\
\hline
\end{tabular}

$+++=$ confluent lysis $;++=$ uncountable discrete plaques; $+=10-20$ plaques.

distinguished among the typing phages and that a third group $(\mathrm{F})$ is also found among these lysogenic cultures. In addition, one phage (S17/211) was found which was not neutralized by any of the available sera. In Table 3 are set out the lytic and serological reactions of each of the twenty-five phage preparations. The bacteriophage preparations are designated by the number of the culture of their origin followed by the number of the strain on which they have been propagated; e.g. 145/211 indicates phage from strain 145 grown on strain 211 . They are arranged in the order of the lysogenic strains from which they originated. It is clear that some of the bacteriophages are identical and that a total of twelve distinct phages were obtained from the six strains. For example, the phages derived from strains 145, 211, S 17, CK5 and 789, which lyse 284, are identical; phages $145 / 211,1339 / 211,1339 / \mathrm{CK} 5$ and $1339 / 789$ are identical; phage $145 / \mathrm{CK} 5$ and $211 / \mathrm{CK} 5$ are identical and so are phages $145 / \mathrm{S} 17$ and $1339 / \mathrm{S} 17$.

Filtrates of the lysogenic strains grown in broth were examined by plating each on all seven indicator strains, and the phage content $/ \mathrm{ml}$. of each filtrate was determined. Each separate phage was isolated from these filtrates and tested in the same manner as the series from the Fisk plates. Individual phages from the two sets of preparations in all cases gave corresponding reactions. Table 4 gives the number of plaques $/ \mathrm{ml}$. of the various filtered broth cultures which developed when the filtrates were titrated with the seven strains.

Other interesting points are revealed in Tables 3 and 4 . The lysogenic strains are each carrying more than one bacteriophage. From strain 145 five phages were obtained, varying in their lytic reactions, in serological type, and in the amount of each present in a filtrate. Strain 211 produced three phages 
of the same serological group differing in lytic patterns and in their titres on sensitive strains. Strain 1339 carried three phages, the group $\mathrm{F}$ phage lysing strain 145 being different from that lysing strains 211 , CK5 and 789 . It should

Table 3. The serological and lytic reactions of twenty-five bacteriophages isolated from six lysogenic strains of staphylococci

\begin{tabular}{|c|c|c|c|c|c|c|c|c|}
\hline \multirow[b]{2}{*}{ Bacteriophage } & \multirow{2}{*}{$\begin{array}{l}\text { Serological } \\
\text { type }\end{array}$} & \multicolumn{7}{|c|}{ Lytic reactions with indicator strains } \\
\hline & & 145 & 211 & 284 & 1339 & Si7 & CK5 & 789 \\
\hline $145 / 211$ & $\mathbf{F}$ & CL & CL & tr. & + & CL & CL & CL \\
\hline $145 / 284$ & B & - & - & CL & - & tr. & - & 一 \\
\hline $145 / 1339$ & B & tr. & + & + & CL & + & CL & + \\
\hline $145 / \mathrm{S} 17$ & A & - & tr. & - & $\overline{C L}$ & CL & - & - \\
\hline $145 / \mathrm{CK} 5$ & $\mathbf{B}$ & ++ & + & $+t$ & SCL & + & CL & - \\
\hline $211 / 284$ & $\mathbf{B}$ & - & 一 & $\mathrm{CL}$ & - & tr. & - & - \\
\hline 211 & B & + & + & + & CL & + & CL & + \\
\hline $211 /$ CK5 & $\mathbf{B}$ & ++ & + & ++ & SCL & + & CL & - \\
\hline $1339 / 145$ & $\mathbf{F}$ & CL & tr. & tr. & 一 & tr. & CL & tr. \\
\hline $1339 / 211$ & F & CL & CL & - & + & CL & CL & CL \\
\hline $1339 / \mathrm{S} 17$ & $\mathbf{A}$ & - & + & - & CL & CL & - & - \\
\hline 1339/CK5 & F & CL & CL & tr. & CL & CL & CL & CL \\
\hline $1339 / 789$ & F & CL & CL & tr. & $\mathrm{CL}$ & CL & CL & CL \\
\hline $\begin{array}{l}\text { S } 17 / 211 \\
\text { S } 17 / 284\end{array}$ & $\underset{\mathbf{B}}{\operatorname{Not} A, B \text { or } F}$ & $\overline{\operatorname{tr}}$ & $\begin{array}{l}\mathrm{CL} \\
\mathrm{tr} .\end{array}$ & $\begin{array}{l}\text { tr. } \\
\text { CL. }\end{array}$ & $\begin{array}{l}\text { tr. } \\
\text { tr. }\end{array}$ & $\begin{array}{l}\operatorname{tr} . \\
\operatorname{tr}\end{array}$ & $\begin{array}{l}+ \\
\text { tr. }\end{array}$ & $\overline{\mathrm{tr}}$ \\
\hline S $17 / 1339$ & $\mathbf{B}$ & tr. & tr. & tr. & CL & tr. & tr. & tr. \\
\hline CK5/145 & $\mathbf{F}$ & CL & tr. & tr. & + & tr. & SCL & - \\
\hline CK5/211 & B & CL & $\mathrm{CL}$ & + & CL & - & + & - \\
\hline CK 5/284 & B & - & - & CL & 一 & - & - & - \\
\hline CK5/1339 & B & CL & $\mathrm{CL}$ & tr. & CL & - & tr. & - \\
\hline CK5/S17 & A & tr. & tr. & tr. & ++ & CL & - & - \\
\hline $789 / 145$ & B & CL & + & SCL & CL & tr. & SCL & - \\
\hline $789 / 211$ & B & $\mathrm{CL}$ & CL & + & CL & 一 & + & - \\
\hline $789 / 284$ & B & - & - & CL & - & - & - & - \\
\hline $789 / 1339$ & B & ++ & CL & + & CL & + & + & + \\
\hline
\end{tabular}

$$
\begin{array}{rlrl}
++ & =\text { numerous discrete plaques. } & \mathrm{CL} & =\text { confluent lysis. } \\
+ & =10-20 \text { plaques. } & \text { SCL } & =\text { semi-confluent lysis. } \\
\text { tr. } & =<10 \text { plaques. } &
\end{array}
$$

\begin{tabular}{|c|}
\hline $\begin{array}{l}\text { Filtrate of } \\
\text { lysogenic } \\
\text { strains }\end{array}$ \\
\hline 145 \\
\hline 211 \\
\hline 1339 \\
\hline S17 \\
\hline CK5 \\
\hline 789 \\
\hline
\end{tabular}

Table 4. Number of plaques/ml. of filtrate of lysogenic strains developing on various indicator strains

\begin{tabular}{rrrrrrr}
\multicolumn{7}{c}{ No. of plaques $/ \mathrm{ml}$. of filtrate on indicator strains } \\
\hline 145 & 211 & 284 & $\mathbf{1 3 3 9}$ & $\mathrm{S} 17$ & $\mathbf{C K 5}$ & $\mathbf{7 8 9}$ \\
0 & 200 & $\mathbf{8 , 5 0 0}$ & $\mathbf{8 0 , 0 0 0}$ & $\mathbf{2 5 0}$ & $\mathbf{1 , 4 0 0}$ & 0 \\
0 & 0 & 500 & $\mathbf{5 0 0 , 0 0 0}$ & 0 & 1,400 & 0 \\
85,000 & 10,000 & 0 & 0 & 10,000 & 3,000 & 500 \\
0 & 20,000 & $\mathbf{2 , 5 0 0}$ & $7,000,000$ & 0 & 0 & 0 \\
$5,800,000$ & 176,000 & 10,000 & 750,000 & 1,250 & 0 & 0 \\
95,000 & 143,000 & 200 & 250,000 & 0 & 0 & 0
\end{tabular}

be noted that the phages $1339 / 211,1339 /$ CK5 5 and $1339 / 789$ will also lyse $\mathrm{S17}$, and that 1339 is carrying two phages, both of which can be isolated on $\mathrm{S} 17$. The 1339/S17 phage of group $\mathrm{A}$ is more specific than the group 
F phage. From strain S17 three phages were obtained in different amounts and of two serological groups. Similarly, strain CK 5 gave phages of four lytic patterns and three serological groups. Phages CK5/211 and CK5/1339 may be identical, the difference in titre when the filtrate was titrated on 211 and 1339 being possibly due to a certain proportion of resistant cells in strain 211. From strain 789, phages of one serological group and four different lytic patterns were obtained.

It has already been shown (Rountree, 1949) that strain 36 carries bacteriophages belonging to two serological groups, so it is evident that the phenomenon of multiple lysogenicity is not confined to this particular group of strains; it is probably widespread among the staphylococci.

It may be questioned whether these phages have been modified by their passage through the indicator strains, since they are of necessity examined after their propagation in strains sensitive to them. However, some strains in the series are lysed by a number of clearly different phages; for example, strain 211 is lysed by the typing phage $3 \mathrm{~B}$ which belongs to serological group $\mathbf{A}$, and by three other phages of different lytic pattern, namely, those from strains 145 and 1339 (group F), from strain S 17 (not group A, B or F) and from strains CK5 and 789 (group B). This suggests that, even if modification during passage does occur, its direction is governed not by some characteristic of the staphylococcus such as lysogenicity, but by the intrinsic character of the phage itself.

Furthermore, it can be shown that when two serological types of bacteriophage are isolated from a given strain, filtrates of such strains before passage of the phages in the sensitive strains do in fact contain the two serological types of phage. For example, the filtrate of $\mathrm{S} 17$, which contains group B phage lysing 1339 and 284 and a phage not of group A, B or F that lyses 211, loses only its group $B$ phage activity on the addition of an appropriate amount of group $B$ phage antiserum. After incubation at $37^{\circ}$ for $4 \mathrm{hr}$., the mixture on plating contains the original amount of phage active against 211 , although phage lysing 1339 or 284 can no longer be demonstrated.

It will be noted that with many of the phages trace reactions, that is, the development of a very few plaques on certain strains, occurred frequently. Since the phages, with the exception of those lysing strain 284, had been grown on lysogenic cultures, it is likely that in some cases these trace reactions were due to contamination of the phage preparation with phage derived from the propagating strain and were not necessarily due to mutation of the phage. An example of this is found in the phage from strain 1339, which on isolation in filtrates has no action on 284. This phage, after growth in strains 145, CK5 and 789 which carry phage lysing 284, gave a few plaques with 284; such plaques may be due to phage released from 145, CK5 and 789 during lysis.

In certain cases, however, it is possible that mutation took place. All the phages propagated on 284 gave identical serological and lytic reactions, being specific for this strain and belonging to serological group B. For the five filtrates in which this phage was found, the ratio of the total amount of group B phage present in the filtrate to the amount of group B phage lysing 
284 was calculated from the values given in Table 4 (Table 5). In the filtrates of strains $211, \mathrm{~S} 17$ and 789 containing only small amounts of the phage lysing 284, the ratios (1000 to 1,3000 to 1 and 2400 to 1 respectively) suggest the possibility of the mutation of the group $B$ phage. Whether this mutation takes place during the release of the phage from the lysogenic cells or during its passage with 284 cannot be determined.

Table 5. The ratio in various filtrates of the total amounts of type $B$ phage to the amount of type $B$ phage specific for strain 284

$\begin{array}{cc}\text { Filtrate of strain } & \text { Type B phage/ml. }(a) \\ 145 & 90,000 \\ 211 & 500,000 \\ \text { S } 17 & 7,000,000 \\ \text { CK5 } & 940,000 \\ 789 & 480,000\end{array}$

$\begin{array}{cc}\text { Phage lysing } & \\ \mathbf{2 8 4} / \text { ml. }(b) & \text { Ratio } a / b \\ 8,500 & 10 \cdot 6 \\ 500 & 1,000 \\ 2,500 & 3,000 \\ 10,000 & 94 \\ 200 & 2,400\end{array}$

Lysogenic strains are sensitive to phages very closely related to those which they carry. For example, the phage 145/211, the phages $1339 / \mathrm{S} 17,1339 / \mathrm{CK} 5$ and 1339/789, and the phage CK5/145, all appear, after passage of the phage through a sensitive strain, to be modified in infectivity, so that the previously resistant cells of the parent become sensitive to them. The alteration in infectivity is not accompanied by any other detectable changes. It seems that the results previously reported (1947a) with cultures S33 and S35 and their phages were due to this alteration in infectivity by passage. Phage from S33 or S35 when isolated by filtration of the culture produces plaques on the sensitive strain, but not on the strain from which it has been prepared. However, after passage of the phage from S 33 through S35, and vice versa, both phages will lyse both S33 and S35 to titre, and no lytic or serological difference can be detected between them.

\section{Infection of sensitive strains by bacteriophage from lysogenic cultures}

By filtration of young broth cultures it has been shown that lysogenic staphylococci release free phage into the surrounding medium. It can therefore be assumed that infection of sensitive strains placed in contact with lysogenic strains is due to the action of this free phage. Questions arise, however, as to what proportion of cells in a lysogenic strain are able to initiate such infection and what mechanism is operative in the release of the phage from the lysogenic cell.

The first question may be answered by the following observations. When $0.02 \mathrm{ml}$. of a suitably diluted young broth culture of a lysogenic strain is spread on agar plates and then covered with an inoculum of a sensitive indicator strain sufficient to give confluent growth, the number of plaques developing in the sensitive strain may be counted after incubation. At the time of inoculation of the plates, a viable count of the number of lysogenic cells is also made. It is then possible to calculate the ratio of lysogenic cells inoculated to the number of plaques developing. It should be noted that this ratio does 
not necessarily indicate the number of cells of the lysogenic culture which are capable of infecting the indicator strain, since under the conditions of the experiment the number of cell divisions which may take place in the lysogenic cells before infection occurs cannot be ascertained. The method is also not very precise because multicellular aggregates of staphylococei giving rise to one colony in the viable count are assumed to have arisen from one coccus. However; the approximate values obtained indicate the order of magnitude of the number of cells initiating infection of a susceptible strain, and therefore presumably capable of releasing bacteriophage. These values have been

Table 6. The number of viable cells of lysogenic strains capable of producing one plaque when tested with certain indicator strains

\begin{tabular}{|c|c|c|c|c|}
\hline \multirow[b]{2}{*}{$\begin{array}{l}\text { Indicator } \\
\text { strain }\end{array}$} & \multirow[b]{2}{*}{ No. } & \multicolumn{3}{|c|}{ Lysogenic strain } \\
\hline & & $\begin{array}{l}\text { Inoculum } \\
10^{6} \text { cells } / \mathrm{ml} \text {. } \\
\text { (a) }\end{array}$ & $\begin{array}{c}\text { Plaques } \\
\text { developing } \\
10^{6} / \mathrm{ml} .(b)\end{array}$ & $\begin{array}{c}\text { Ratio } \\
a / b\end{array}$ \\
\hline 1339 & S17 & 4,800 & 1,800 & $2 \cdot 7$ \\
\hline 211 & S 17 & 4,800 & 17 & 280 \\
\hline 284 & S17 & 4,800 & $0 \cdot 16$ & 30,000 \\
\hline 145 & 1339 & 40,000 & 45 & 900 \\
\hline 211 & 1339 & 40,000 & 110 & 360 \\
\hline S17 & 1339 & 40,000 & 1,400 & 28 \\
\hline S17 & S 14/1 & 1,000 & 1 & 1,000 \\
\hline & $\mathrm{S} 14 / 2$ & 750 & 4.5 & 170 \\
\hline & S14/3 & 5,200 & 13 & 380 \\
\hline & S 14/4 & 6,000 & 15 & 400 \\
\hline & $\mathrm{S} 14 / 5$ & 6,000 & $12 \cdot 5$ & 480 \\
\hline & $\mathrm{S14} / 6$ & 2,650 & 9 & 290 \\
\hline & S $14 / 7$ & 2,000 & 6 & 340 \\
\hline & $\mathrm{S} 14 / 8$ & 850 & 2 & 420 \\
\hline & $\mathrm{S} 14 / 9$ & 3,250 & 2 & 1,600 \\
\hline & $\mathrm{S} 14 / 10$ & 1,500 & 4.5 & 300 \\
\hline & $\mathrm{S} 14 / 11$ & 17,700 & 66 & 270 \\
\hline
\end{tabular}

determined for three strains: S17 against three indicator strains, 1339 against three indicator strains and $S 14$ against $S 17$. The ratio was also determined for eleven single-colony cultures of strain S14. In Table 6 the number of cells inoculated and of plaques developing have been expressed as numbers $/ \mathrm{ml}$. of the broth culture used; the final column gives the number of cells in the inoculum producing one plaque.

Three different values were obtained with strain S17 according to the indicator strains used, and these values correspond well with the relative amounts of the three phages present in the filtrates of this strain (Table 4). The value for phage lysing 1339 is exceptionally high. Three different values were also obtained for strain 1339. The values for the eleven cultures of S14 varied from one plaque/170 cells inoculated to $1 / 1600$, and are probably within the limits of error of the method.

The conclusion may be drawn that phage is released only from a certain proportion of cells in a given lysogenic strain. This proportion is fairly constant for any given strain, but it varies from phage to phage when more than one 
phage occurs in a particular strain. The figures do not, however, indicate whether a single cell of a strain that produces more than one type of phage may at a given moment itself produce more than one type. Further, it is not possible to say definitely whether the phage is released by lysis of a small percentage of cells or whether phage may be extruded from cells which remain viable. Strain $\mathrm{S} 17$, which produces large amounts of phage active against 1339, would be a convenient strain for an investigation of this problem by singlecell culture methods.

\section{Permanence of lysogenicity}

In general terms it may be stated that bacteriophage may be detected in every cell of a lysogenic strain of staphylococcus, and that no treatment has so far been successful in making the strain non-lysogenic. The strains in this collection were grown in broth for periods varying from 1 to 5 years and during this time were plated and repicked from single colonies on numerous occasions; yet the twenty-seven lysogenic strains are still lysogenic. On one occasion, strain $\mathrm{S} 17$ was plated out, and a hundred of the resulting single colonies were picked into broth and retested for lysogenicity. All proved to be lysogenic. Numbers of single colonies from other strains in the series have also been tested with similar results.

Some of the bacteriophages carried by these strains were sensitive to heat when in cell-free filtrates, being destroyed by heating at $49^{\circ}$ for $1 \mathrm{hr}$. When, however, the lysogenic strains carrying these phages were heated at this temperature for $2 \mathrm{hr}$. and replated, all the resultant colonies proved to be lysogenic.

Some of the bacteriophages carried by these strains are citrate-sensitive, being unable to lyse sensitive strains in the presence of $1 \%$ sodium citrate. When, however, the lysogenic strains carrying these citrate-sensitive phages were grown for 7-10 days in broth containing $1 \%$ sodium citrate and were plated at intervals during this incubation period, bacteriophage could be demonstrated in all single colonies tested.

Finally, growth of a lysogenic strain in serum containing specific antibodies for the bacteriophage carried by the strain did not remove the lysogenicity. Very small inocula of strains S14, S17 and 1339 suspended in broth with equal volumes of undiluted high-titre serum were each incubated for 4-5 hr. at $37^{\circ}$ until turbidity could be detected and were plated out. Every colony tested after incubation overnight was lysogenic, up to eighty colonies from a single plate being tested on various occasions.

\section{DISCUSSION}

The results clearly indicate that the association of bacteriophage and lysogenic cell is very intimate. Phage is to be found in each single bacterial colony from a lysogenic staphylococcal strain. Since agents such as heat and antiserum, which destroy the bacteriophage when it is in the free state, do not alter the lysogenicity of the strain, an intracellular method of passage of the phage in such strains is postulated such that the daughter cells of each staphylococcal 
fission each receive at least one phage particle. It is possible that bacteriophage, which is predominantly nucleoprotein in composition, is associated with the nuclear apparatus of the lysogenic cell in such a way that regular distribution of the phage to the daughter cells occurs at cell division.

The relation between bacteriophage and lysogenic cell is, however, variable, since only a certain proportion of cells in each lysogenic strain liberates bacteriophage. This proportion varies from strain to strain and may be very small. The usual proportion appears to be of the order of 1 cell in every 1000. No examples have been found in which every cell in a strain releases phage. Two mechanisms of the release may be postulated. Either the phage is extruded by cells which remain viable: or the modal equilibrium between phage and cell is unstable, and in a certain proportion of the infected cells the phage multiplies as it does in sensitive cells; as a consequence the cell is lysed and its phage liberated. Since this second postulate has as its basis a known method of phage liberation, whereas the first is highly speculative, liberation by lysis is the most probable method of release of phage from lysogenic cells. The fact that liberated phage, after passage through a sensitive strain but apparently otherwise unaltered, can be shown in a number of cases to be fully infective for all the cells of the original lysogenic strain, may be significant in this connexion. Burnet \& Lush (1936) found indications that the liberation of their mutant $C^{\prime}$ lysogenic phage from ageing cultures was always associated with the destruction of the coccus from which it was derived.

The data in Tables 1 and 3 make it clear that the possession of lysogenicity does not render the staphylococci resistant to the lytic action of bacteriophages. Of the twenty-seven strains listed in Table 1 , only two have so far proved resistant to the action of the phages available. As pointed out by Williams Smith (1948a), the results obtained with the staphylococci cannot be explained on the basis of the 'penetration' hypothesis postulated by Delbrück (1945) for the Bacterium coli $\mathbf{T}$ bacteriophages. The material presented in this paper also suggests that interference effects are very limited among staphylococci, many of which show multiple lysogenicity, and may consist solely of inhibition of lysis by the bacteriophage carried by the strain, not extending even to very closely related or apparently identical phages. The possession of lysogenicity may be only partly responsible for the various reaction patterns obtained when a series of typing phages acts upon a number of closely related staphylococci.

Williams Smith $(1948 a, b)$ showed that after the development of resistance to various phages derived from lysogenic strains, originally non-lysogenic strains became lysogenic and were changed in their reactions to a number of typing phages. The reactions of such variants were similar to those of the lysogenic strains producing the resistance-inducing phages. He concluded that acquired phage resistance was responsible for the classification of many initially identical strains as different phage types. In certain sensitive strains and in some resistant strains, however, he was unable to obtain evidence of lysogenicity. My results suggest even greater complication. The strains differ in their reactions to the typing phages, but the typing phages belong to a serological group different from that of the majority of the phages carried by these 
strains. The typing phages acting on these strains belong to serological group A (Rountree, 1949), while the sole phage of this serological character which has been isolated from only some of these strains lyses strain $\mathrm{S} 17$ and is restricted in its activity. The differing reactions given by the strains with the typing phages cannot, therefore, be attributed 'directly to the fact that they are carrying one or more of these typing phages. Furthermore, strain 284, which showed a very narrow phage specificity, was apparently not lysogenic.

The intrinsic characters of the staphylococcal cell which determine sensitivity to specific bacteriophages is still unexplained, but the available evidence suggests that it is not primarily due to the possession of lysogenicity.

This work was carried out under a grant from the Australian National Health and Medical Research Council.

My thanks are due to Dr G. S. Wilson, Director of the Public Health Laboratory Service, for permission to work in the Staphylococcal Reference Laboratory, and to Dr V. D. Allison for his kindness in placing at my disposal all the facilities of the Reference Laboratory and all his extensive knowledge of the phages. I would also wish to thank Mr G. Heimer for much valuable technical assistance.

\section{REFERENCES}

Burnet, F. M. \& Lush, D. (1935). The staphylococcal bacteriophages. J. Path. Bact. 40, 455.

Burnet, F. M. \& Lush, D. (1936). Induced lysogenicity and mutation of bacteriophage within lysogenic bacteria. Aust. J. exp. Biol. med. Sci. 14, 27.

Callow, B. R. (1922). Bacteriophage phenomena with Staph. aureus. J. infect. Dis. 30, 643.

Christie, R. \& Keogh, E. V. (1940). Physiological and serological characteristics of staphylococci of human origin. J. path. Bact. 51, 189.

Cowan, S. T. (1939). Classification of staphylococci by slide agglutination. J. Path. Bact. 48, 169.

Delbrück, M. (1945). Interference between bacterial viruses. III. The mutual exclusion effect and the depressor effect. J. Bact. 50, 151.

Fisk, R. 'T. (1942). Studies on staphylococci. I. Occurrence of bacteriophage carriers among strains of Staph. aureus. J. infect. Dis. 71, 153.

Rountree, P. M. (1947a). Staphylococcal bacteriophages. I. The effect of penicillin on staphylococcal bacteriophages. Aust. J. exp. Biol. med. Sci. 25, 9.

Rountree, P. M. (1947b). Staphylococcal bacteriophages. II. Bacteriophage absorption by staphylococci. Aust. J. exp. Biol. med. Sci. 25, 203.

Rountree, P. M. (1949). The serological differentiation of staphylococcal bacteriophages. J. gen. Microbiol. 3, 164.

Tond, E. W. \& Hewitr, L. F. (1932). A new culture medium for the production of antigenic streptococcal haemolysin. J. Path. Bact. 32, 973.

WiLliams SMITH, H. (1948a). Investigations on the typing of staphylococei by means of bacteriophage. I. The origin and nature of lysogenic strains. J. Hyg., Camb., 46, 74 .

Williams Smith, H. (1948b). Investigations on the typing of staphylococci by means of bacteriophage. II. The significance of lysogenic strains in staphylococcal type designation. J. Hyg., Camb., 46, 82.

Wilson, G.S. \& Atkinson, J.D. (1945). Typing of staphylococci by the bacteriophage method. Lancet, $1,647$.

(Received 2 June 1948) 